\title{
E1 futuro de las relaciones entre el Brasil y los Estados Unidos
}

Helio Jaguaribe

\section{HISTORIA Y PROYECGIŌN}

Las relaciones del Brasil con los Estados Unidos fueron, comprensiblemente, de modesta importancia hasta fines del siglo xIX. En ese período, para el Brasil fueron importantes las relaciones internacionales determinadas por el Imperio portugués durante la fase colonial. Después de la Independencia, tuvieron relevancia las relaciones con Gran Bretaña, como potencia predominante de la época y con Argentina, como rival regional.

El vertiginoso desarrollo de Argentina, desde 1880 hasta la Primera Guerra Mundial, llevó al Brasil a recelar que aquel país pudiese articular exitosamente un gran frente antibrasileño en América del Sur. Tal situación condujo al Brasil a buscar una relación especial con los Estados Unidos, que neutralizase los riesgos de rina coalición antibrasileña en este Continente. Para los Estados Unidos, esa relación especial con el Brasil constituía una forma de romper una posible unidad latinoamericana y de conducir las relaciones hemisféricas al formato de un panamericanismo bajo la hegemonía norteamericana.

Los objetivos políticos ya mencionados perdieron énfasis entre Ias dos guerras, pero persistirán de forma Iatente. Por otro lado; creció continuamente el intercambio comercial entre el Brasil y los Estados Unidos, convirtiéndose este país en nuestro principal cliente $y$ abastecedor.

Desde 1950 hasta 1964, en el curso de su primera fase de desarrollo planificado, el Brasil intentó que los Estados Unidos se convirtieran en la principal fuente externa de apoyo financiero para sus proyectos y los de América Latina. Esa perspectiva fue poco exitosa. En el segundo gobierno de Vargas (1950-54), la Comisión Mixta Brasil-Estados Unidos no logró de parte del gobierno de Eisenhower la implementación de los financiamientos pendientes 
que ya había comprometido el gobierno de Truman. Kubitscheck, todavía durante el gobierno de Eisenhower, lanzó sin éxito su operación panamericana. La sustancia de la propuesta sería retomada más tarde por Kennedy, pero bajo control norteamericano. En el gobierno de Goulart, el Ministro de Hacienda, Santiago Dantas, logró en condiciones modestísimas los financiamientos por los que Iuchó.

Desde 1964 a 1973, en virtud de la orientación de los gobiernos militares en el Brasil, se creó una fuerte solidaridad ideológica. Ella condujo a una política de "fronteras ideológicas" en América Latina y en Africa, que estrechó mucho las relaciones políticas brasileño-norteamericanas. EI Brasil no extrajo ningún beneficio concreto de esa política $y$, por el contrario, su posición en el Tercer Mundo se deterioró en forma seria y gratuita.

Desde 1974 hasta nuestros días se ha ido manifestando un creciente desacuerdo político en el plano internacional entre el Brasi] y los Estados Unidos. Esa situación será analizada sucintamente en la siguiente sección de este breve estudio. También se hizo evidente que el sector financiero público norteamericano, que fue un banquero excesivamente modesto en la primera fase de desarrollo planificado en el Brasil, tomaría una posición aún más secundaria en las condiciones actuales.

Al proyectar para los próximos tres años las probables características de las relaciones entre el Brasil y Ios Estados Unidos, cabe anticipar tres aspectos principales. Durante lo que resta de la Adrínistración Reagan, las relaciones políticas serán de acentuadas divergencias aunque, probablemente, no revistan un carácter antagónico. No obstante, se espera que el Gobierno norteamericano intente llevar a cabo peligrosas maniobras divisionistas en América Latina, buscando inducir a las Fuerzas Armadas de Argentina a intervenir militarmente en América Central. Las relaciones económicas entre los gobiernos estarán marcadas por una profunda oposición de concepciones, y se situarán operacionalmente en un nivel modesto. El Brasil, que ya hace algunos años dejó de buscar importantes financiamientos públicos en los Estados Unidos, intentará minimizar las restricciones comerciales y financieras que anticipa recibir del Gobierno norteamericano (proteccionismo y "graduación"). En cambio, en el plano privado, las relaciones deberán ser muy activas. El sistema financiero privado norteamericano continuará jugando un papel importante, si bien proporcionalmente decreciente, en la atención de las demandas brasileñas. El intercambio comercial será también importante, aunque igualmente decreciente en términos relativos. Deberán acentuarse mucho más las activas relaciones que el Brasil mantiene con el sistema universitario norteamericano. 


\section{SITUACIÓN AGTUAI $\mathrm{X}$ PERSPEGTIVAS}

Las divergencias políticas entre el Brasil y los Estados Unidos, que se venían agravando desde 1974, con la readopción de una política externa independiente por parte del Brasil, y que se volvieron particularmente serias con la Administración Reagan, se derivan fundamentalmente de tres factores: 1) distintas y conflictivas visiones del mundo actual; 2) falta de conexión entre lo que, a largo plazo, tiene el Brasil para ofrecer y los Estados Unidos para demandar; 3) discrepancia entre lo que los Estados Unidos proponen al Brasil y las conveniencias de éste.

\section{Visiones del mundo}

La esencia de las divergencias y conflictos entre los dos países, en la visión actual del mundo, surge de la concepción que ambos tienen de la presente crisis internacional y de los remedios para superarla. Los Estados Unidos, especialmente con Reagan, pretenden que, en último análisis, sólo hay actualmente un gran conflicto: la confrontación entre un Occidente libre y pacífico y una Unión Soviética totalitaria y militarmente expansionista, que se está orientando para obtener una victoria militar sobre el Occidente. Ante tal situación, es importante detener a plazo más largo a la Unión Soviética, a través de la edificación de una absoluta superioridad militar occidental. Desde. Iuego, a corto plazo importa impedir de todas las formas posibles nuevos avances estratégicos o tácticos de la Unión Soviética. De ahí, por ejemplo, el propósito de impedir, si es necesario por medio de una intervención militar, el derrocamiento de las oligarquías centroamericanas, como en el caso del Salvador. Igualmente, de ahí proviene el intento que principia a visualizarse de atraer a las Fuerzas Armadas de Argentina hacia una peligrosa política de intervención militar en América Central.

Por el contrario, Brasil considera que el mundo está doblemente afectado por conflictos Este-Oeste y Norte-Sur, cada cual con caráctex específico, sin poderse reducir uno al otro. En la medida relativamente apreciable en que se interrelacionan los dos conflictos, el Brasil entiende que el conflicto Norte-Sur tiene más efecto condicionante sobre el Este-Oeste que lo contrario. Lo que lleva a las fuerzas de liberación a buscar, en contrapartida, ayuda soviética, es el apoyo norteamericano al colonialismo o a obsoletas oligarquías locales. A esto se añade que, dadas las características de ambos conflictos, el Brasil considera que el equilibrio del terror mantendrá relativamente congelado - retórica aparte- el conflicto Este-Oeste, en cuanto que el conflicto Norte-Sur está agravándose continuamente y exige, pues, prontas medidas por parte de la comunidad internacional. 


\section{Oferta y demanda}

La falta de conexión entre lo que, a largo plazo, Brasil tiene para ofrecer y los Estados Unidos para demandar, crea un intervalo no menos largo que el precedente para las relaciones entre los dos países.

EI Brasil contemporáneo se caracteriza realmente por el hecho de que se ha formado en él un amplio consenso nacional en cuanto a dos cuestiones básicas. La primera se refiere al propósito de casi todos los brasileños, de transformar al Brasil lo más rápidamente posible en una gran sociedad industrial moderna, abierta, democrática y socialmente ecuánime. La segunda cuestión, que es objeto de igual consenso, se refiere al hecho de.que los brasileños consideran que su país está dotado de las condiciones necesarias para alcanzar tal objetivo hasta el fin del siglo y, en proporción significativa, en los próximos diez años. Por ello, y excluyendo para mayor simplicidad del análisis la ardua hipótesis de un desarrollo puramente endógeno, el Brasil requiere de una amplia cooperación internacional que lo ayude a superar su crisis energética, compense la crisis de divisas conectada con ella y acelere su proceso de desarrollo general y de autonomización tecnológica.

A cambio de una cooperación internacional a largo plazo, que atienda las demandas brasileñas a las que ya nos referimos, el Brasil se propone ofrecer al mundo, además de otros ítem, a largo plazo y en proporciones significativas a partir de la próxima década: 1) fuentes energéticas renovables más baratas que el petróleo, como etanol, metanol y aceites vegetales sustitutivos del diesel; 2) alimentos naturales e idustrializados; 3) bienes de capital (acero, cemento, etc.), equipo pesado y manufacturas de amplio consumo popular (textiles, electrodomésticos, etc.). Dadas las características de la economía norteamericana, los Estados Unidos tienen una demanda nula, o poca, para tal tipo de oferta. En efecto, los Estados Unidos no se disponen a ser grandes importadores de etanol o de aceites vegetales combustibles. Confían en su capacidad de continuar importando petróleo, $\mathrm{y}$ disponen de suficientes sustitutos de procedencia doméstica, como hidrógeno o energía nuclear. En materia de alimentos, los Estados Unidos son, y por largo tiempo continuarán siéndolo, grandes exportadores. Tampoco les interesan posibles ofertas brasileñas de bienes de capital, equipo y manufacturas. Las condiciones de la politica interna en los Estados Unidos conducen, por el contrario, a subsidiar a los productores ineficientes de tales ítem, directamente o a través de medidas proteccionistas. 


\section{Propuesta norteamericana}

Finalmente, no es menor la discrepancia entre lo que los Estados Unidos tienen para proponer al Brasil en el plano internacional y las conveniencias de éste. La propuesta norteamericana para el Brasil consiste, básicamente, en la invitación a ingresar en el círculo más restringido del club occidental capitalista, con un status semejante al del Canadá. Las multinacionales norteamericanas que operan en el Brasil exportarían aI resto del mundo los productos industriales que ofrece el Brasil, compitiendo con los productores norteamericanos en sus mercados externos. El Brasil se abastecería en el mercado abierto internacional, que está bajo predominio norteamericano, de recursos financieros, insumos varios y tecnología. Dentro de ese régimen, el Brasil participaría del sistema políticomilitar de contención de la Unión Soviética. Asegurarían la defensa del Atlántico Sur las bases norteamericanas en el Brasil, conjuntamente con la participación del Brasil, con los Estados Unidos, Argentina y la Unión Sudafricana, en un sistema aeronaval común.

Si consideramos tal propuesta, que representa sólo una sofisticación de la política de "fronteras ideológicas" de los años 1964-73, a partir de un punto de vista brasileño, ella traería para el Brasil supuestos beneficios de carácter meramente retóricos y graves y efectivos daños económicos y políticos. El Brasil, tanto económica como políticamente, perdería su inserción en el Tercer Mundo sin dejar, por eso, de convertirse en un verdadero país del Primer Mundo.

En efecto, en último análisis sucede que la condición de país occidental del Brasil proviene de su cultura, implantada por los descubridores y desarrollada en estrecho contacto con Europa y no de sus posiciones políticas pro occidentales, aunque tenga y mantenga estas últimas por opción propia. No es por concesión de terceros que el Brasil es un país occidental. Tal condición no es otorgable por. ninguna negociación. Son los propios esfuerzos internos para occidentalizarse de un país de cultura no occidental, como ocurrió con la Turquía de Kemal o el Japón Meiji, los que conducen, o bien a un resultado predominantemente frustrado, como en el caso de la primera, o a una occidentalización tecnológica no respaldada por una correspondiente visión del mundo como en el segundo caso, lo que suscita un grave dualismo interior.

\section{Primeros y Terceros Mundos}

EI Occidentalismo no confiere, per se, la condición de miembro del Primer Mundo. Esta se deriva, además, de un proceso previo y necesariamente largo, en que se combinan el desarrollo económicotecnológico con el desarrollo político-social. En el próximo siglo el Brasil podrá, eventualmente, convertirse en un miembro del Pri- 
mer Mundo. En verdad, los brasileños desean esa conversión, pero es preciso que se comprenda que, para el futuro, la condición de miembro del Primer Mundo, además de la cultura occidental y del alcance previo de un elevado nivel de desarrollo económico-tecnológico y político-social (que Brasil, en la mejor de las hipótesis sólo podrá alcanzar a principios del próximo siglo), va a depender igualmente de las condiciones internacionales y geoeconómicas que van a prevalecer en el primer tercio del siglo xxr. En efecto, todo indica que no son proyectables a largo plazo los niveles de afluencia que existen ahora en el Primer Mundo. Por lo tanto, en el futuro, Ios países más desarrollados deberán convertirse a estilos distintos de vida, basados más en la dimensión pública que en la privada, y más orientados para consumos culturales que materiales.

Por otro lado, en el caso brasileño es importante tener presente el hecho de que una de las condiciones necesarias para que el país supere la crisis de carácter económico y sociopolítico en que se encuentra actualmente, consiste en reducir los niveles de consumo de sus elites, elevar los patrones de vida de las grandes masas y, con respecto al resto del mundo, mantener una disciplina económica que le permita expandirse interna y externamente. Para que llegue a ser un gran exportador de combustibles vegetales, de alimentos y de bienes industriales, el Brasil tendrá que producirlos en condiciones comparativamente más ventajosas que las de sus competidores.

Por eso, la condición de miembro del Tercer Mundo, que corresponde ahora efectivamente al Brasil (independientemente de su condición de país occidental) no puede ser superada por un mero esfuerzo de rotulación propio o de terceros ni puede, pragmáticamente, ser rehusada. No sólo se trata del hecho, además obvio, de que la solidaridad real del Brasil con el Tercer Mundo le facilite Ios intercambios económicos y políticos con esa área deI mundo, en la cual nuestro país dispone de sustanciales ventajas comparativas. También y principalmente, se trata del hecho muy objetivo y de carácter habilitatorio de que la posibilidad, por parte del Brasil, de ser un gran exportador de los ítem que se han mencionado y de constituirse internamente con una sociedad industrial, moderna, abierta, democrática y socialmente ecuánime, depende de que el país mantenga en niveles moderados el patrón de consumo de las elites y de que reduzca significativamente el intervalo entre tal patrón y el de las grandes masas.

\section{Gonclustones}

El Brasil está dirigiendo al mundo -y se verá cada vez más compelido a hacerlo en el curso de la década del 80- una gran demanda de cooperación internacional para alcanzar su autonamización energética y tecnológica y ultimar su desarrollo económico-social. 
Durante toda esta década, el Brasil necesitará recibir más recursos de los que podrá generar, tanto para enfrentar las tareas internas de los programas de sustitución energética y de su desarrollo general cuanto, externamente, para equilibrar su balanza de pagos. A cambio de esa asistencia internacional, el Brasil está preparado, desde ahora, para dar al mundo, en volúmenes crecientes que alcanzarán grandes proporciones a partir de la próxima década, una importante contribución, en condiciones comparativamente ventajosas, en términos de 1) combustibles de origen vegetal; 2) alimentos naturales e industrializados; 3) bienes de capital, equipos pesados y manufacturas de amplio consumo popular.

Como ya se vio, esa oferta brasileña interesa poco o nada a Ios Estados Unidos. En compensación, esa oferta interesa mucho a Europa Occidental y al Japón, a los países de la OPEP, al Tercer Mundo en general y, más moderadamente, a la Unión Soviética y Ios paises del bloque.

Europa y Japón, sin petróleo ni biomasa, tendrán que importar una cuota significativa de combustibles vegetales, hasta que desarrollen -como deberán hacerlo- otras fuentes energéticas alternativas. Ese interés euronipón es de tal orden que deberá permitir, mediante las negociaciones apropiadas, una importante participación de recursos de aquellos países en la instalación de las facilidades productivas brasileñas. Lo mismo cabe decir en lo tocante a Europa, al Japón y a los países de la opep en materia de alimentos.

En parte, el Tercer Mundo será cliente del Brasil en cuanto a combustibles vegetales y alimentos $y$, ampliamente, para bienes de capital, equipos y manufacturas. El factor limitativo para un intercambio en grande escala será la reducida capacidad de importación del Tercer Mundo. Negociaciones multilaterales que comprenderán a los países de la OPEP y a los euronipones podrán ampliar significativamente el ámbito de esas transacciones.

En tal cuadro, todo indica que las relaciones brasileño-norteamericanas tenderán a experimentar en el futuro modificaciones mucho más acentuadas que las que se han observado en los últimos años. Los intereses y valores comunes que vinculan de forma permanente al Brasil con el mundo occidental, independientemente de que el Brasil aspire a convertirse en un miembro del Primer Mundo, o bien lograr hacerlo efectivamente, conducirán al país a conservarse firmemente en el ámbito del campo occidental y a mantener estrechas relaciones de cooperación con Ios Estados Unidos. Estas serán más en el ámbito del sector privado que en el público, más económicos que políticos y tendrán creciente significación cultural y científico-tecnológica. 